\title{
Inversion polymorphisms in Trimerotropis pallidipennis (Orthoptera): clinal variation along an altitudinal gradient
}

\author{
Viviana A. Confalonieri and \\ Pablo C. Colombo
}

Laboratio de Genética, Departamento de Ciencias Biológicas, Facultad de Ciencias Exactas y Naturales, Universidad de Buenos Aires, Intendente Güiraldes y Costanera Norte (1428), Buenos Aires, Argentina.

Six populations of Trimerotropis pallidipennis located along an altitudinal gradient in the Antinaco-Los Colorados valley (La Rioja, Argentina), were cytologically analysed. The male karyotype consists of 23 chromosomes (22+XO) with three long pairs submetacentric, the $\mathrm{X}$-chromosome metacentric and the remaining ones basically acrocentric. Populations from La Rioja were polymorphic for seven pericentric inversions. Correlations between chromosome frequencies and altitude were statistically tested. In most cases, variables were either positively or negatively related in a significant fashion. As a consequence, mean populational heterozygosis (measured as the mean number of heteromorphic bivalents per individual per population) was also positively correlated with altitude. These results suggest that altitude (or other correlated environmental variable) may exert a differential selective pressure on coadapted gene blocks in the mutually inverted sequences. The possible relation of these results with the centralmarginal model is discussed.

\section{INTRODUCTION}

Inversion polymorphisms cause functional crossover supression within the mutually inverted segments of heterozygotes, and as a consequence of this they are regarded as chromosomal devices that preserve coadapted, tightly linked, genes from recombination (Carson, 1958; Hewitt, 1979; John, 1983; Brussard, 1984). These gene complexes called "supergenes" are prone to suffer progressive genetic differentiation that may enhance the adaptation of natural populations to local conditions. The adaptive significance of paracentric inversion polymorphisms in Drosophila is well documented, mainly through seasonal, ecological and clinal variation studies (Brussard, 1984; Sperlich and Pfriem, 1986). Despite this huge body of evidence, studies concerning adaptive significance of inversion polymorphisms are less well developed in grasshoppers (White, 1958, 1973; Lewontin and White, 1960; Hewitt, 1979; John, 1983).

Studies in South American populations of Trimerotropis pallidipennis revealed pericentric inversions and B-chromosome polymorphisms (Mesa, 1971; Vaio et al., 1979; Goñi et al, 1985; Confalonieri, 1988); while North American popu- lations, on the contrary, are apparently monomorphic (White, 1951; Weissman and Rentz, 1980). Goñi et al. (1985) made cytological studies on seven populations collected along a $650 \mathrm{~km}$ long transect in northern Patagonia (Argentina). Based on their data, the authors concluded that inversion polymorphisms follow geographical patterns that are not correlated with climatic nor phytogeographic regions.

In the present work, six populations located along an altitudinal gradient in the Famatina valley (La Rioja, Argentina) were analysed cytologically with the purpose of detecting correlations between inversion frequencies and ecological and/or climtic variables in a smaller geographic scale.

\section{MATERIALS AND METHODS}

Six populations of $T$. pallidipennis (Oedipodinae: Acrididae) were collected along the Famatina valley (La Rioja; Argentina) in the following localities; Las Gredas (LG), Famatina (F), Chilecito $(\mathrm{CH})$, Nonogasta $(\mathrm{N})$, Vichigasta (V) and Catinzaco $(\mathrm{C})$; the corresponding altitudes are given in table 1 and fig. 1 . These populations are sited along a $109 \mathrm{~km}$ long altitudinal gradient. Male 


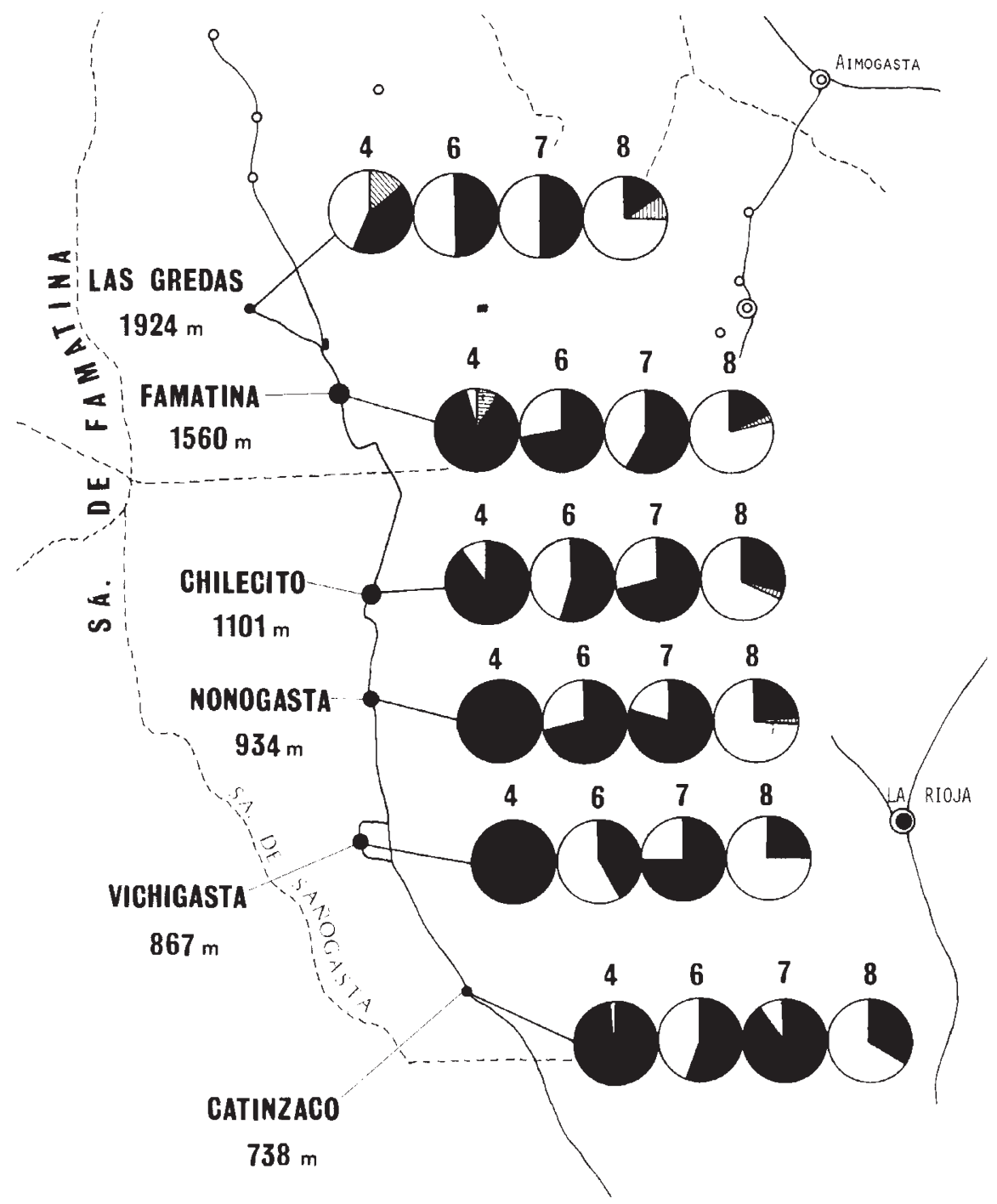

Figure 1 Populations sampled of Trimerotropis pallidipennis from La Rioja (Argentina) and its corresponding altitudes. Circles indicate relative frequencies of each medium sized chromosome morphology. 害: 4SM1, 8A.

individuals were dissected in the field and testes were fixed in 3:1 ethanol:acetic acid. Subsequently, 103 individuals from all populations were cytologically analysed; the numbers of individuals analysed from each population are also listed in table 1 . Testes were squashed in lactopropionic orcein.

\section{RESULTS}

\section{Karyotype}

The male karyotype of $T$. pallidipennis consists of 23 chromosomes $(22+\mathrm{XO})$. Pairs $1-3$ are long (L), pairs 4-8 are medium sized (M) and pairs 9-11 are small (S). All three long chromosomes are submetacentric, the $\mathrm{X}$ chromosome is metacentric, and the remaining ones are basically acrocentric (Vaio et al, 1979).

\section{Inversion systems}

The populations analysed are polymorphic for seven pericentric inversions. Chromosome 4 displays three morphologies: submetacentric (SM1), acrocentric (A), and inverted acrocentric (AI) (the two latter can be distinguished only in the 
Table 1 Observed frequencies of chromosome morphologies and of B-carrier males from Las Gredas (LG), Famatina (F), Chilecito $(\mathrm{CH})$, Nonogasta $(\mathrm{N})$, Vichigasta $(\mathrm{V})$ and Catinzaco $(\mathrm{C})$ populations belonging to Trimerotropis pallidipennis. A = basic acrocentric; $\mathrm{AI}=$ inverted acrocentric; $\mathrm{SM}=$ submetacentric, $\mathrm{M}=$ metacentric; $\mathrm{H}=$ mean heterozygosis; $4 \mathrm{AI}$ and $4 \mathrm{~A}$ frequencies were obtained according to Hardy-Weinberg equilibrium, because homozygotes are indistinguishable

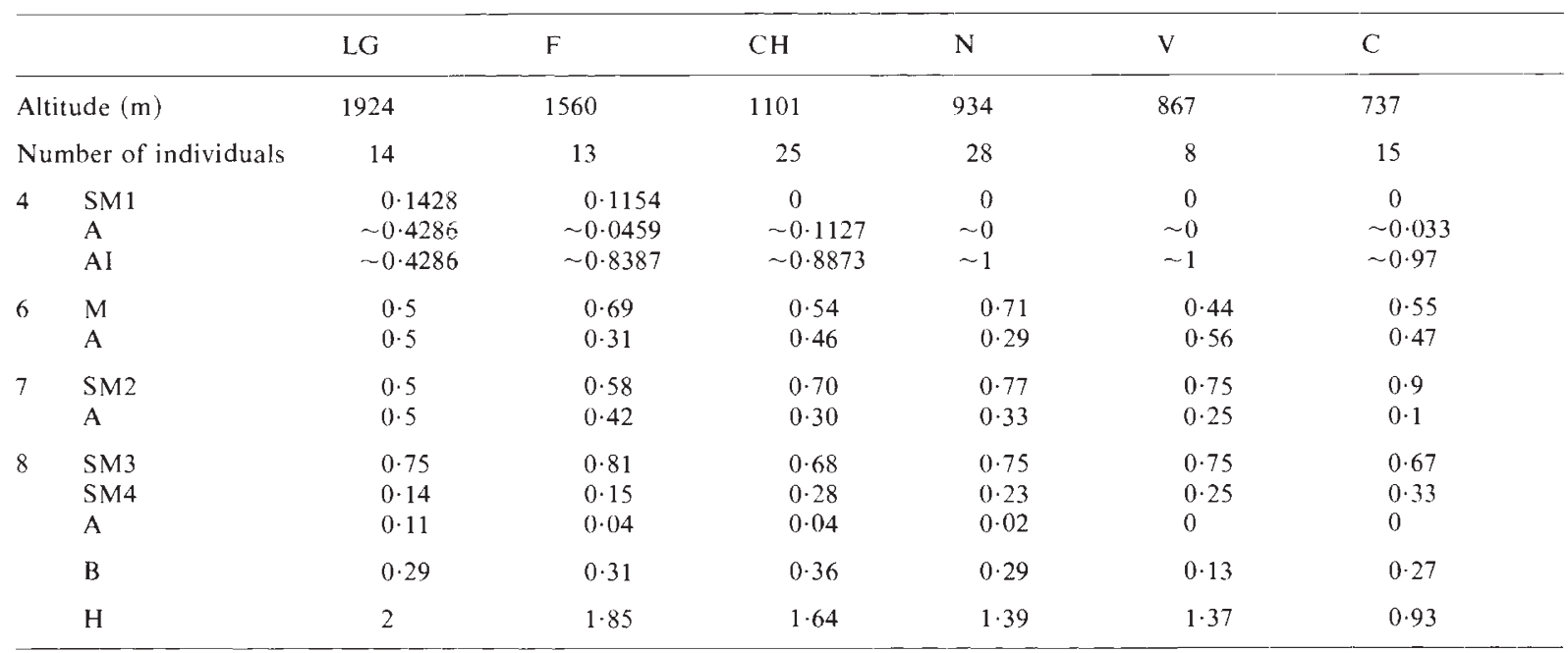

heteromorphic bivalents of heterozygotes) (fig. 2). The remaining four medium sized chromosomes are very similar in size; three of them are polymorphic for four pericentric inversions. These inversions shifted the basic acrocentric morphology into many median or submedian forms, that are fairly distinguishable from each other. Consequently, all medium chromosomes could be readily differentiated according to the morphology they showed. Thus, chromosome 6 (number arbitrarily assigned) had two morphologies: basic acrocentric (A) and metacentric (M); chromosome 7 also presented two morphologies: basic acrocentric (A) and submetacentric (SM2), and chromosome 8 displayed three morphologies, one of them acrocentric and the remaining two submetacentric (SM3 and SM4) (fig. 2).

Sequences SM2 and SM4 could not be readily distinguished. But, given the low frequency of the latter, almost all SM4 carrier individuals were SM3/SM4 heterozygotes (because the probability of SM4/SM4 homozygotes ocurring in the population was very low) (table 1 ), so that bivalent 8 could be easily identified too.

All six populations also carried a polymorphism for an acrocentric, partially euchromatic B chromosome, whose morphology is the same as that reported by Vaio et al (1979), Goñi et al. (1985) and Confalonieri (1988). Its frequencies are listed in table 1.

Table $2 r$ coefficients and $P$ value obtained when chromosome morphology frequencies were correlated with altitude. $\mathrm{A}=$ acrocentric; $\mathrm{AI}=$ inverted acrocentric; $\mathrm{SM}=$ submetacentric

\begin{tabular}{|c|c|c|c|}
\hline $\begin{array}{l}\text { Chromosome } \\
\text { number }\end{array}$ & $\begin{array}{l}\text { Chromosome } \\
\text { morphologies }\end{array}$ & $r$ & $P$ \\
\hline 4 & A & $0 \cdot 81^{*}$ & $0.05-0.01$ \\
\hline 4 & AI & $-0.91^{* * *}$ & $\sim 0.01$ \\
\hline 4 & $\mathrm{SM} 1$ & $0.97^{* * *}$ & $0 \cdot 01-0 \cdot 001$ \\
\hline $6^{1}$ & A & $-0 \cdot 23$ & $0.70-0.60$ \\
\hline $7^{1}$ & A & $0.91^{* *}$ & $\sim 0.01$ \\
\hline 8 & SM3 & 0.56 & $0 \cdot 30-0 \cdot 20$ \\
\hline 8 & SM4 & $-0 \cdot 89^{*}$ & $0.02-0.01$ \\
\hline 8 & $\mathrm{~A}$ & $0.93^{* * *}$ & $0.01-0.001$ \\
\hline
\end{tabular}

${ }^{1} r$ coefficients of $6 \mathrm{M}$ and $7 \mathrm{SM} 2$ sequences are similar to $6 \mathrm{~A}$ and $7 \mathrm{~A}$ but with inverse slope. 


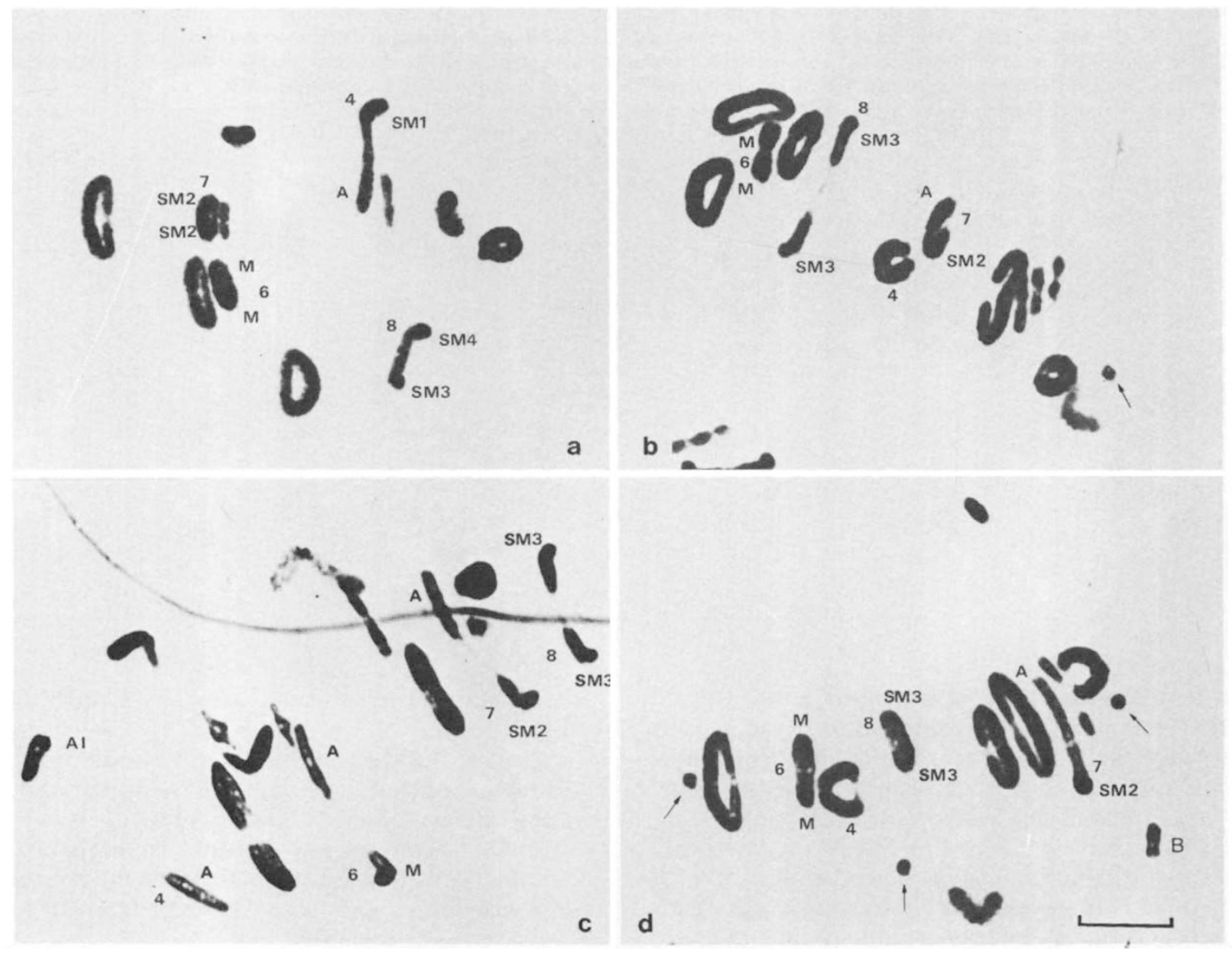

Figure 2 Metaphase I cells from Trimerotropis pallidipennis males. Chromosome morphologies of polymorphic medium sized bivalents are indicated ( No. 4,6,7 and 8). $\mathrm{A}=$ basic acrocentric; $\mathrm{M}=$ metacentric; $\mathrm{SM}=$ submetacentric. b, d; arrows indicate an extra chromosome found in one individual (in d, only one of the chromosomes arrowed corresponds to the supernumerary). $\mathrm{Bar}=10 \mu \mathrm{m}$.

\section{Clinal variation}

The frequencies of each sequence per population are graphically represented in fig. 1. These values, together with mean populational heterozygosis $(\vec{H})$ per population are listed in table 1 . The values of $\bar{H}$ were estimated as the mean number of heteromorphic bivalents per individual per population. From this table, it is apparent that inversion frequencies, in some cases, increase or decrease gradually from population to population. With the aim of determining whether this clinal variation of frequencies is associated with any environmental variable, the frequency of each inversion was correlated with altitude (table 2 ). These results indicate that inversion frequencies vary in a sig- nificant fashion along with altitude, except for the sequences $8 \mathrm{SM} 3,6 \mathrm{~A}$ and $6 \mathrm{M}$.

Some frequencies are positively correlated with height, like $8 \mathrm{~A}, 7 \mathrm{~A}, 4 \mathrm{~A}$ and $4 \mathrm{SM} 1$, and others are negatively correlated: $8 \mathrm{SM} 4,7 \mathrm{SM} 2$ and $4 \mathrm{AI}$.

It is worth noting that some chromosome morphologies, namely the $8 \mathrm{~A}, 4 \mathrm{~A}$ and $4 \mathrm{SM} 1$ are completely lost in populations situated at lower altitudes. As a consequence of this, it is expected that chromosome variability would be strongly diminished. Hence a correlation study between mean heterozygosity $(\bar{H})$ and altitude was made. There is a positive and highly significant correlation between both variables, which means that high-altitude populations have a larger amount of chromosome variability (table 1, fig. 3). 


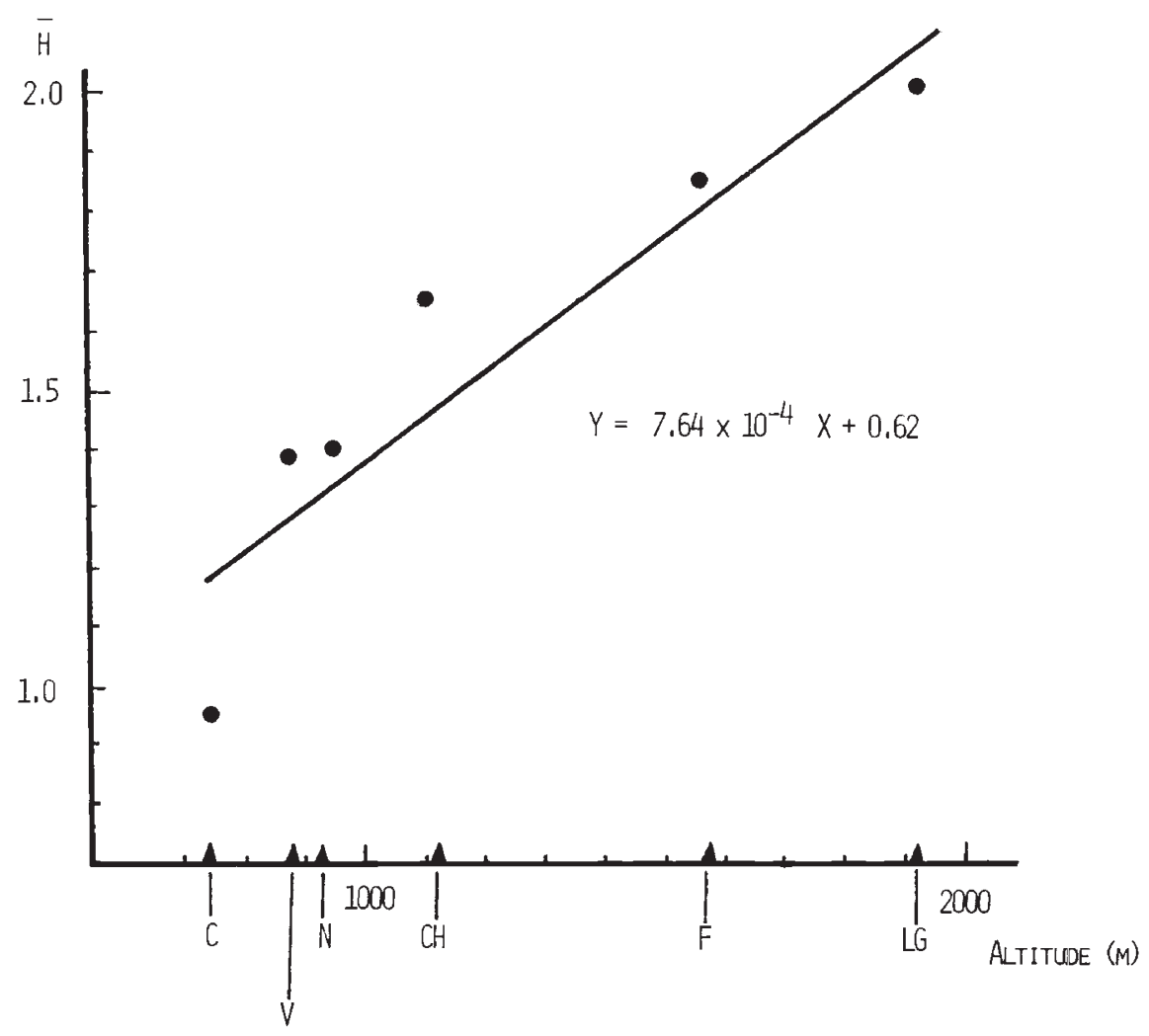

Figure 3 Mean populational heterozygosis $(\bar{H})$ vs. altitude corresponding to Las Gredas (LG), Famatina (F), Chilecito (CH), Nonogasta $(\mathrm{N})$, Vichigasta (V) and Catinzaco (C) populations of Trimerotropis pallidipennis.

\section{DISCUSSION}

Correlation of traits with environmental factors is one of the commonest and oldest methods in detecting selection. Although a correlation does not necessarily imply a cause-and-effect relationship, it is useful in determining what traits and what environmental variables are suspected of being engaged in a selective process (Endler, 1986).

In the present work, a clinal variation was found in most of the inversions analyzed along the Famatina valley. This cline is parallel to an altitudinal gradient along this valley which determines the highly significant correlations between the frequencies of chromosome inversions and altitude. Hence, it is suggested that altitude (and/or other correlated variables such as temperature, oxygen saturation, atmospheric pressure, etc) exert differential selective pressures on coadapted gene blocks. These, as was pointed out by Weissman (1976) in T. pseudofasciata, may differ genetically from those of the mutually inverted sequences and would be therefore better adapted to different environments.

Goñi et al. (1985) support the idea that inversion polymorphisms in T. pallidipennis follow geographic patterns of distribution that would not fit into phytogeographic nor climatic regions. This idea is in apparent discordance with our findings. However, it is possible that both views are not mutually exclusive but complementary. In fact, Burla et al. (1986) found a microdifferentiation of an inversion polymorphism in Drosophila subobscura along a slope in the Alps that is superimposed over broader trends of karyotype variation determinec by historical factors like migration. This might be also the case in $T$. pallidipennis. Since Goñi et al. (1985) performed no microdifferentiation analysis (their study is based on seven populations collected along a $650 \mathrm{~km}$ long transect in northern Patagonia) this possibility cannot be excluded.

From this study there is also evidence of a marked decrease of heterozygosity toward lower 
altitudes (table 1; fig. 3). This is specially relevant in the context of the "central-marginal model", which supports the notion that ecologicaly and/or geographically central populations of many species of Drosophila show a higher degree of inversion polymorphism than marginal ones (Brussard, 1984). Notwithstanding the validity of this model in Drosophila species, it does not seem to be of universal applicability in grasshoppers. A clear example of marginal-central patterns of chromosomal variability among grasshoppers was performed in T. helferi (Schroeter, 1968, cited by John, 1983), and in Trimerotropis pseudofasciata (Weissman, 1976), but no clear central-marginal trend was found in $T$. suffusa and $T$. gracilis (White, 1973). In the grasshopper Leptysma argentina a polymorphic centric fusion was discovered that produces a strong intra- and interchromosomal reduction of chiasma frequency; hence, its genetic effects (i.e., a marked decrease of recombination) are similar to those produced by an inversion (Colombo, 1987). A distribution pattern that is clearly reminiscent of a central-marginal model was found (Colombo, submitted). Yet the centric fusion has also exophenotypic effects (Colombo, submitted) so it is possible that the causes of fusion distribution are more complex.

In the case of $T$. pallidipennis there is no evidence that higher altitudes are ecologically more central than lower ones. Anyway, population cytogenetic studies in $T$. pallidipennis are not well enough developed to definitively discard or confirm the central-marginal model. A wider geographical approach (currently being undertaken) is needed for a better comprehension of the adaptive significance of inversion polymorphisms in this species.

Acknowledgements The authors are grateful to Prof. Juan $\mathrm{H}$. Hunziker, Dr Juan C. Vilardi and Lic. Maria I. Remis for valuable comments and critical reading of the typescript; they are also indebted to Dr. Ricardo Ronderos for the identification of Trimerotropis pallidipennis specimens. Financial support from the Consejo Nacional de Investigaciones Científicas y Técnicas and Secretaría de Ciencia y Técnica (Argentina) through grants to Drs J. H. Hunziker and C. A. Naranjo is gratefully acknowledged.

\section{REFERENCES}

BRUSSARD, P. F. 1984, Geographic patterns and environmental gradients: the central-marginal model revisited. Ann. Rev. Ecol. Syst., 15, 25-64.
BURLA, H., IUNGEN, H. AND BÄCHLI, G. 1986. Population structure of Drosophila subobscura. Non-random microdispersion of inversion polymorphism on a mountain slope. Genetica, 70, 9-15.

CARSON, H. L. 1958. Response to selection under different conditions of recombination in Drosophila. Cold Spring Harb. Symp. Quant. Biol., 23, 291-306.

COLOMB(), P. ( 1987 . Effects of centric fusions on chiasma frequency and position in Leptysma argentina (Acrididae: Orthoptera). I. Spontaneous and stable polymorphi centric fusions. Genetica, 72, 171-179.

CONFALONIERJ, V. A. 1988. Effects of centric-shift polymorphisms on chiasma conditions in Trimerotropis pallidipennis (Oedipodinae: Acrididae). Genetica (in press).

ENOLER, 1. A. 1986. Natural selection in the Wild. Princeton University Press, Princeton, New Jersey.

GOÑI, B., de VAIO, E. S., BELTRAMI, M., LEIRA, M. S., CRIVEL, M., PANZERA, F., CASTELLANOS, P. AND BASSO, A. 1985. Geographic patterns of chromosomal variation in populations of the grasshopper (Trimerotropis pallidipennis) from southern Argentina. Can. J. Genet. Cytol., 27, 259-271.

HEWITT, G. M. 1979. Animal Cytogenetics, Vol. 3, Insecta I. Orthoptera. B. John (ed.) Gebruder Borntraeger, BerlinStuttgart.

JOHN, B. 1983. The role of chromosome change in the evolution of orthopteroid insects. In Chromosomes in the Evolution of Eukaryotic Groups, Vol. 1, Sharma, A. K. and Sharma, A. N. (eds), C.R.C. Press, Flordia, pp. 1-114.

LEWONTIN, R. C. AND WHITE, M. J. D. 1960. Interaction between inversion polymorphisms of two chromosome pairs in the grasshopper Moraba scurra. Evolution, 14, $116-129$.

MESA, A. 1971. Polimorfismo cromosómico en Trimerotropis pallidipennis (Orthoptera-Acridoidea-Oedipodinae). Rev. Per. Entomol., 14, 2.

SPERLICH, D. ANI PFRIEM, P, 1986. Chromosom al polymorphism in natural and experimental populations. In The genetics and biology of Drosophila, vol. 3e, Academic Press Inc, London.

VAIO, L.S.de, GOÑI, B., REY, C. 1979. Chromosome polymorphism in populations of the grasshopper Trimerotropis pallidipennis from southern Argentina. Chromosoma, 71, 371386.

WEISSMAN, D. B. 1976. Geographical variability in the pericentric inversion systems of the grasshopper Trimerotropis pseudofasciata. Chromosoma, 55, 325-347.

WEISSMAN, D. B. AND REN 2 , C. F. 1980. Cytological, morphological and crepitational characteristics of the Trimerotropines (Aerochroreutes, Cyrcotetix and Trimerotropis). Trans. Amer. Ent. Soc. 106, 253-272.

WHITE, M. J. D. 1951. Cytogenetics of Orthopteroid insects. Adv. Genet. 4, 207-330.

WHITE, M. J. D. 1958. Restriction on recombination in grasshopper populations and species. Cold Spring. Harb. Symp. Quant. Biol, 23, 307-317.

WHITE. M. J. D. 1973. Animal Cytology and Evolution, 3rd edn. Cambridge University Press, London. 